\title{
Factors Affecting the Color of Herbaceous Peony
}

\author{
Mingyue Bao, Minmin Liu, Qingxia Zhang, Tonglin Wang, and Xia Sun \\ College of Horticulture, Shandong Agricultural University, State Key Laboratory of Crop Biology, \\ Tai'an Shandong 271018, China \\ Jinguang Xu \\ Shandong Academy of Forestry, Jinan 250014, China
}

AdDitional INDEX wORDs. condensed tannin, HPLC, intracellular environment, microstructure, Paeonia lactiflora, pigment

\begin{abstract}
Herbaceous peony (Paeonia lactiflora Pall.) is a well-known ornamental plant with abundant flower colors. However, our understanding of the underlying mechanisms of flower color formation is limited. In this study, a wild sample of herbaceous peony (collected from Heze, China) and eight cultivars with different colors were selected for experimental investigation. The Royal Horticultural Society Color Chart was used to determine flower color, and the anatomic structure; cell sap pH value; moisture content (MC); condensed tannin content (Ct); soluble sugar and soluble protein content of the petals; and content and composition of anthocyanin, flavonoids, and carotenoids in the petals were examined. 1) In the white, pinkish white, pale purple, purplish pink, and reddish purple cultivars, deeper color was associated with greater total amounts of anthocyanin (TA). Hypochromic effects were observed for kaempferol-7-O-glucoside (Km7G), myricetin-3-rhamnoside (My3R), and luteolin-7-O-glucoside (Lu7G). The accumulation of quercetin-3-O-glucoside (Qu3G) and lutein affected yellow color formation in the petals. 2) There are papillate epidermal cells in the petals of the wild $P$. lactiflora sample, 'Lanyucangjin', and 'Dongjingnvlang'. 3) Cell sap pH and MC of the petals of white, pinkish white, pale purple, and purplish pink cultivars were greater than those of the purplish red and most of the reddish purple cultivars. 4) The $\mathrm{Ct}$ was greatest in the purplish red cultivars, whereas no condensed tannins were detected in the white, pinkish white, and pale purple cultivars. 5) There were no significant correlations among soluble sugar content, soluble protein content, and the other physiological indications.
\end{abstract}

Flower color is an important characteristic of ornamental plants that results from substances in the petal cells, such as flavonoids, carotenoids, and alkaloids; and various intracellular environmental factors such as the $\mathrm{pH}$ value and metal ion content (Lapidot et al., 1999; Yoshida et al., 2009). There are three major groups of plant pigments - flavonoids, carotenoids, and alkaloids - and flavonoids are divided further into anthocyanins, flavonoids, and flavonols (Zhao et al., 2005). Studies on yellow camellia (section Chrysantha Chang), medicinal chrysanthemum (Chrysanthemum morifolium Ramat), beach rose (Rosa rugosa Thunb.), and tree peony (Paeonia suffruticosa Andr.) have shown that the content and components of anthocyanin are closely related to flower color (Jiang et al., 2019; Ma et al., 2016; Zhang et al., 2015b, 2018). The intermolecular cocoloration of anthocyanin and accessory pigments can also affect flower color; the chemical bonding energy between these factors can improve the stability of anthocyanin for changing flower color (Zhuang et al., 2018). Sugars are the main energy source and precursors for anthocyanin synthesis, which regulates the anthocyanin content (Zhang et al., 2015a), and proteins are the products of functional gene expression that control changes in the sugar content (He et al., 2010).

Herbaceous peony (Paeonia lactiflora) is a perennial herbaceous plant that exhibits varied flower types and colors. In Tai'an, China (lat. $117^{\circ} 06^{\prime} \mathrm{N}$, long. $36^{\circ} 11^{\prime} \mathrm{E}$ ), it blooms from

Received for publication 6 Jan. 2020. Accepted for publication 25 Mar. 2020. Published online 27 April 2020.

This work was supported by grants from the National Natural Science Foundation of China (31670663) and Shandong Agricultural Engineering Forest Tree Breeding Project Corpus for High-grade Garden Flower Breeding (2130106)

X.S. is the corresponding author. E-mail: sunxia65@sina.com.

This is an open access article distributed under the CC BY-NC-ND license (https://creativecommons.org/licenses/by-nc-nd/4.0/). late April to mid May. Studies on herbaceous peony flower color have focused mainly on the classification and identification of anthocyanin, and analyses of the anthocyanin synthesis pathway and anthocyanin stability (Jia et al., 2008; Zhong et al., 2012). The petal structure and cell contents of herbaceous peonies have never been investigated thoroughly.

In this study, we selected wild plants and eight representative cultivars of herbaceous peony with different colors. We documented the anatomic structure of the petals and determined the cell sap $\mathrm{pH}$ value, water content, $\mathrm{Ct}$, soluble sugar and soluble protein contents, and pigment content and composition. We also analyzed the indexes influencing flower color formation to identify the key physiological factors underlying different colors and to elucidate the molecular mechanisms of herbaceous peony flower color, which will aid future breeding efforts of new cultivars.

\section{Materials and Methods}

Plant materials. The experiments were carried out from Apr. 2018 to Sept. 2019 at four locations at Shandong Agricultural University, Tai'an, China: Garden Center Laboratory of the Horticultural Experiment Station (lat. $36^{\circ} 19^{\prime} \mathrm{N}$, long. $117^{\circ} 12^{\prime}$ E), Gardening Center Laboratory and the Life Science Center (lat. $36^{\circ} 17^{\prime} \mathrm{N}$, long. $117^{\circ} 16^{\prime} \mathrm{E}$ ), Herbaceous Peony of the Horticulture Test Station (lat. $36^{\circ} 16^{\prime} \mathrm{N}$, long. $117^{\circ} 16^{\prime} \mathrm{E}$ ), and Experimental Center of the Academy of Life Sciences (lat. $36^{\circ} 16^{\prime} \mathrm{N}$, long. $117^{\circ} 16^{\prime} \mathrm{E}$ ). The wild sample of herbaceous peony and eight cultivars (Xuefeng, Jinzanciyu, Lanyucangjin, Dongjingnvlang, Honglou, Dafugui, Foguangzhuying, and Zilingjinpao) were grown for 3 years after vegetative propagation. From 19 Apr. to 7 May 2018, we sampled the plants from 0900 to $1100 \mathrm{HR}$ on days when the ground temperature was more than $20^{\circ} \mathrm{C}$ and there was no cloud cover. We collected 
only completely opened flowers and used the fresh petals from the middle layer as samples. 'Jinzanciyu' and 'Foguangzhuying' have variable petal shapes within each flower, so we sampled the inner and outer petals from both cultivars. Fresh samples were used to make paraffin sections, and to determine the cell sap $\mathrm{pH}$ value and $\mathrm{MC}$. The remainder of the fresh samples was frozen in liquid nitrogen and preserved at $-80^{\circ} \mathrm{C}$.

Flower COlOR, PETAL CELl SAP PH, AND MC. The Royal Horticultural Society Color Chart (Royal Horticultural Society, 2015) was used to determine flower color (Li et al., 2018). Five grams of fresh petals were cut into small segments, ground into a homogenate with a mortar and quartz sand, and the cell sap $\mathrm{pH}$ was measured with a $\mathrm{pH}$ meter (PB-10; Sartorius, Goettingen, Germany) (Xue et al., 2015). Four grams of fresh petals were dried in an electric constant-temperature air blast drying box (DHG-9145a; Shanghai Yiheng Science and Technology, Shanghai, China) at $80^{\circ} \mathrm{C}$ for $12 \mathrm{~h}$. Finally, the constant weight and $\mathrm{MC}$ were calculated as $\mathrm{MC}=(\mathrm{FW}-\mathrm{DW}) / \mathrm{FW} \times 100 \%$, where FW is the fresh weight and DW is the dry weight.

Petal Microstructure. Paraffin sections were prepared according to the methods described by Cheng (2008). We selected fresh petals and cut off the middle portion and fixed them with FAA fixative [formalin:glacial acetic acid:50\% ethanol (5:5:90)] for $48 \mathrm{~h}$ after removing the debris. Sections were made using a pathological microtome (RM2016; Shanghai Leica, Shanghai, China). After dewaxing and washing, the sections were stained with safranin for $2 \mathrm{~h}$, decolorized with alcohol, and stained with fast green for 6 to $20 \mathrm{~s}$. The sections were then immersed in a dimethylbenzene solution for $5 \mathrm{~min}$, and sealed with neutral resin. The sections were observed using an optical microscope (Eclipse E100; Nikon, Tokyo, Japan), and imaged and analyzed with an imaging system (DS-U3, Nikon). An eyepiece micrometer and image-processing software (Image-Pro Plus 6.0; Media Cybernetics, Rockville, MD) were used to measure the thickness of the petal cross-sections, cytoderm, and parenchymatous tissue; and the length and width of the epidermal cells.

Biochemical constituents of the petals. The soluble sugar content was determined via the anthrone colorimetric method (Cang and Zhao, 2013). A fresh sample $(0.3 \mathrm{~g})$ was added to $10 \mathrm{~mL}$ distilled water and boiled twice for $30 \mathrm{~min}$. After filtration, the volume was adjusted to $50 \mathrm{~mL}$ with distilled water. One milliliter of the extract was combined with $1 \mathrm{~mL}$ distilled water $(2 \mathrm{~mL}$ distilled water was added to the control group), $0.5 \mathrm{~mL}$ ethyl acetate anthrone solution, and $5 \mathrm{~mL}$ sulfuric acid. The mixture was heated in boiling water for $1 \mathrm{~min}$ then cooled to room temperature, and the absorbance spectra were measured at $630 \mathrm{~nm}$ using an ultraviolet and visible spectrophotometry (UV-Vis) spectrophotometer (UV-2450; Shimadzu, Kyoto, Japan).

The soluble protein content was determined via the Coomassie brilliant blue method (Yu, 2014). A fresh sample (0.5 g) was added to $5 \mathrm{~mL}$ phosphate buffer $\left(0.05 \mathrm{~mol} \cdot \mathrm{L}^{-1}, \mathrm{pH} 7.8\right)$ and centrifuged at $4{ }^{\circ} \mathrm{C}$ for $20 \mathrm{~min}\left(11,354 g_{\mathrm{n}}\right)$. Twenty microliters of supernatant was combined with $3 \mathrm{~mL}$ Coomassie brilliant blue solution $(20 \mu \mathrm{L}$ distilled water was added to the control group), and after $2 \mathrm{~min}$, the absorbance spectra were measured at $595 \mathrm{~nm}$ using a UV-Vis spectrophotometer (UV-2450).

The $\mathrm{Ct}$ was determined using the vanillin-hydrochloric acid method (Yao and Ti, 2010). A fresh sample (0.2 g) was added to $5 \mathrm{~mL} 70 \%$ methanol and, after $24 \mathrm{~h}$, the sample was centrifuged at $4{ }^{\circ} \mathrm{C}$ for $20 \mathrm{~min}\left(2575 \mathrm{~g}_{\mathrm{n}}\right)$. The supernatant $(0.5 \mathrm{~mL})$ was combined with $3 \mathrm{~mL} \mathrm{4 \%} \mathrm{vanillin} \mathrm{methanol} \mathrm{solution} \mathrm{and} 1.5 \mathrm{~mL}$ concentrated hydrochloric acid. The mixture was extracted in a $20-{ }^{\circ} \mathrm{C}$ water bath in darkness for $20 \mathrm{~min}$, and the absorbance spectra were measured at $510 \mathrm{~nm}$ using a UV-Vis spectrophotometer (UV-2450). Catechin was used as a standard.

The TA was determined by $\mathrm{pH}$-differential spectrophotometry (Wang, 2015). A fresh sample $(0.25 \mathrm{~g})$ was added to $5 \mathrm{~mL}$ $1 \%$ methanol hydrochloride solution. After $24 \mathrm{~h}$ of extraction in darkness at $4{ }^{\circ} \mathrm{C}$, the sample was centrifuged at $4{ }^{\circ} \mathrm{C}$ for $10 \mathrm{~min}$ $\left(6591 g_{n}\right)$. One milliliter of supernatant was combined with 4 $\mathrm{mL} \mathrm{KCl}$ buffer ( $\mathrm{pH} 1.0)$ and $4 \mathrm{~mL}$ sodium acetate buffer $(\mathrm{pH}$ 4.5). After extraction at $4{ }^{\circ} \mathrm{C}$ in darkness for $15 \mathrm{~min}$, absorbance was measured at 510 and $700 \mathrm{~nm}$ using a UV-Vis spectrophotometer (UV-2450). The control group was treated with the same blank extract without extract as the experimental group.

The total amount of flavonoids (TF) was determined by spectrophotometry (Wang, 2015). A fresh sample $(0.1 \mathrm{~g})$ was added to $10 \mathrm{~mL} 95 \%$ ethanol. After ultrasonic extraction at $20{ }^{\circ} \mathrm{C}$ for $60 \mathrm{~min}$, the sample was centrifuged at $4{ }^{\circ} \mathrm{C}$ for $10 \mathrm{~min}$ $\left(6591 g_{n}\right)$ and was then left to rest for $4 \mathrm{~h}$. Two milliliters of supernatant was combined with $4 \mathrm{~mL}$ distilled water and $1 \mathrm{~mL}$ $5 \%$ sodium nitrite. After $6 \mathrm{~min}, 1 \mathrm{~mL} \mathrm{10 \%}$ aluminum nitrate was added and, after an additional $6 \mathrm{~min}, 10 \mathrm{~mL} \mathrm{5 \%} \mathrm{sodium}$ hydroxide was added. The volume was adjusted to $25 \mathrm{~mL}$ with distilled water, and the absorbance spectra were measured at $500 \mathrm{~nm}$ after $15 \mathrm{~min}$ using an UV-Vis spectrophotometer (UV2450). The control group was treated with the same blank extract without extract as the experimental group.

The total amount of carotenoids (TC) was also determined by spectrophotometry ( $\mathrm{Li}$ et al., 2000). A fresh sample $(0.2 \mathrm{~g})$ was added to $10 \mathrm{~mL}$ extract [anhydrous ethanol:acetone $(1: 1)$ ] and, after $\approx 30 \mathrm{~h}$ of extraction in darkness at $4{ }^{\circ} \mathrm{C}$, the plant tissue turned white. Absorbance was measured at 665, 649, and $470 \mathrm{~nm}$ using an UV-Vis spectrophotometer (UV-2450). The control group was treated with the same blank extract without extract as the experimental group.

According to the results from previous studies (Liu et al., 2019; Yang et al., 2018; Zhao et al., 2016; Zhong et al., 2012) and those from preliminary tests, we selected particular biochemical substances and measured their contents. These included eight anthocyanins [cyanidin-3-O-glucoside (Cy3G), cyanidin-3,5-di-O-glucoside (Cy3G5G), peonidin-3-O-glucoside (Pn3G), peonidin-3,5-di-O-glucoside (Pn3G5G), pelargonidin-3-O-glucoside (Pg3G), pelargonidin-3,5-di-O-glucoside (Pg3G5G), delphinidin-3-O-glucoside (Dp3G), and delphinidin-3,5-di-O-glucoside (Dp3G5G)], seven flavonol glycosides [kaempferol-3-O-glucoside (Km3G), Km7G, isorhamnetin-3O-glucoside (Is3G), isorhamnetin-3-O-galactoside (Is3Gal), Qu3G, quercetin-7-O-glucoside (Qu7G), and My3R], one flavonoid glycoside $(\mathrm{Lu} 7 \mathrm{G})$, and two carotenoids $(\beta$-carotene and lutein).

We used the high-performance liquid chromatography (HPLC)-UV method to identify the anthocyanins, flavonoids, and carotenoids.

For the anthocyanin measurement, $0.2 \mathrm{~g}$ fresh sample was added to $6 \mathrm{~mL}$ extract [methanol:water:hydrogen chloride (70:29.9:0.1)]. After $24 \mathrm{~h}$ of extraction at $4{ }^{\circ} \mathrm{C}$ in darkness, the sample was extracted by ultrasound for $30 \mathrm{~min}$, centrifuged at $4{ }^{\circ} \mathrm{C}$ for $10-15 \mathrm{~min}\left(148 \mathrm{~g}_{\mathrm{n}}\right)$, and filtered using $0.22-\mu \mathrm{m}$ filter paper. HPLC was performed using a liquid chromatograph (LC 20-a) with a 5- $\mu \mathrm{m}, 4.6-\times 100-\mathrm{mm}$ column (Venusl XBP C18; Agela Technologies, Tianjin, China). The mobile phase was $8 \%$ 
formic acid-water $[(0.08 \%$ trifluoroacetic acid $)$ :acetonitrile $(0.08 \%$ trifluoroacetic acid) (95:5)], the flow rate was 0.6 $\mathrm{mL} \cdot \mathrm{min}^{-1}$, and the detection wavelength was $520 \mathrm{~nm}$. The standard concentration was $1 \mu \mathrm{g} \cdot \mathrm{mL}^{-1}$, the solvent was $8 \%$ formic acid-water $(0.08 \%$ trifluoroacetic acid $)$, and the injection volume was $20 \mu \mathrm{L}$. The standards used were cyanidin-3-Oglucoside chloride, cyanidin-3,5-diglucoside, peonidin-3-Oglucoside chloride, peonidin-3,5-O- $\beta$-diglucopyranoside, pelargonidin-3-O- $\beta$-D-glucoside, pelargonidin-3,5-diglucoside, delphinidin-3- $\beta$-D-glucoside, and delphinidin-3,5diglucoside.

For the flavonoid measurement, $0.3 \mathrm{~g}$ fresh sample was added to $5 \mathrm{~mL} 0.2 \%$ butylated hydroxytoluene acetone solution for extraction. After $24 \mathrm{~h}$ of extraction at $4{ }^{\circ} \mathrm{C}$ in darkness, the sample was extracted by ultrasound for 10 to $20 \mathrm{~min}$, centrifuged at $4{ }^{\circ} \mathrm{C}$ for $10 \mathrm{~min}\left(2575 g_{\mathrm{n}}\right)$, and filtered using $0.22-\mu \mathrm{m}$ filter paper. HPLC was performed using a liquid chromatograph (LC 20-a) with a 5- $\mu \mathrm{m}, 4.6-\times 150-\mathrm{mm}$ column (Inertsil ODS-3, Shimadzu). The mobile phase was $1 \%$ formic acid:methanol $(1: 1)$, the flow rate was $0.8 \mathrm{~mL} \cdot \mathrm{min}^{-1}$, the detection wavelength was $355 \mathrm{~nm}$, and the column temperature was $35^{\circ} \mathrm{C}$. The standard concentration was $1 \mu \mathrm{g} \cdot \mathrm{mL}^{-1}$ and the injection volume was $10 \mu \mathrm{L}$. The standards were $\mathrm{Km} 3 \mathrm{G}$, kaempferol-7-O- $\beta$-Dglucoside, Is $3 \mathrm{G}$, Is $3 \mathrm{Gal}, \mathrm{Qu} 3 \mathrm{G}$, quercetin-7-O- $\beta$-D-glucoside, myricitrin, and luteolin-7-O- $\beta$-D-glucoside.

For the carotenoid measurement, $0.5 \mathrm{~g}$ fresh sample was added to $25 \mathrm{~mL}$ extract [ $80 \%$ methanol:dimethyl sulfoxide (1:1)]. After $24 \mathrm{~h}$ of extraction at $4{ }^{\circ} \mathrm{C}$ in darkness, the sample was extracted by ultrasound for $30 \mathrm{~min}$, centrifuged at $4{ }^{\circ} \mathrm{C}$ for 10 $\min \left(2085 g_{\mathrm{n}}\right)$, and filtered using $0.22-\mu \mathrm{m}$ filter paper. HPLC was performed using a liquid chromatograph (LC 20-a) with a 5- $\mu \mathrm{m}$, 4.6- $\times 100-\mathrm{mm}$ column (Venusl XBP C18, Agela Technologies). The mobile phase was an acetonitrile:methanol:Tris- $\mathrm{HCl}$ buffer
$0.05 \mathrm{~mol} \cdot \mathrm{L}^{-1}(72: 8: 3, \mathrm{pH} 7.5)$, methanol:n-hexane (5:1), the flow rate was $0.8 \mathrm{~mL} \cdot \mathrm{min}^{-1}$, the detection wavelength was $440 \mathrm{~nm}$, and the column temperature was $35^{\circ} \mathrm{C}$. The standard concentration was $1 \mu \mathrm{g} \cdot \mathrm{mL}^{-1}$ and the injection volume was $10 \mu \mathrm{L}$. The standards were $\beta$-carotene and lutein.

Statistical analysis. All measurements were repeated three times. IBM Statistics (version 19.0; IBM, Armonk, NY) was used for one-way analysis of variance and correlation analyses, and the least significant difference test and Duncan's new multiple range test were used to compare the differences between samples. The plots were generated in Microsoft Excel (Office 2016; Microsoft, Redmond, WA) and Origin 2017 (OriginLab, Northhampton, MA).

\section{Results}

Color Determination. Flower color was determined from the Royal Horticultural Society Color Chart (Royal Horticultural Society, 2015). The result is shown in Fig. 1. 'Xuefeng' is white; the outer petals of 'Jinzanciyu' is pinkish white and the inner petals are yellow; 'Lanyucangjin' is pale purple; 'Dongjingnvlang' is purplish pink; the wild sample, 'Honglou', 'Dafugui', and 'Foguangzhuying' are reddish purple; and 'Zilingjinpao' is purplish red.

Pigments in the test Samples. As shown in Fig. 2, a deeper color in the white, pinkish white, pale purple, purplish pink, and reddish purple cultivars was associated with greater amounts of anthocyanin. The TA was the greatest in the outer petals of reddish purple 'Foguangzhuying' and was the least in white 'Xuefeng'. The composition of anthocyanin is presented in Table 1. Pg3G5G and Pn3G5G were the main anthocyanins in white 'Xuefeng', pinkish white 'Jinzanciyu' (outer petals), and yellow 'Jinzanciyu' (inner petals). Pn3G5G and Cy3G were the
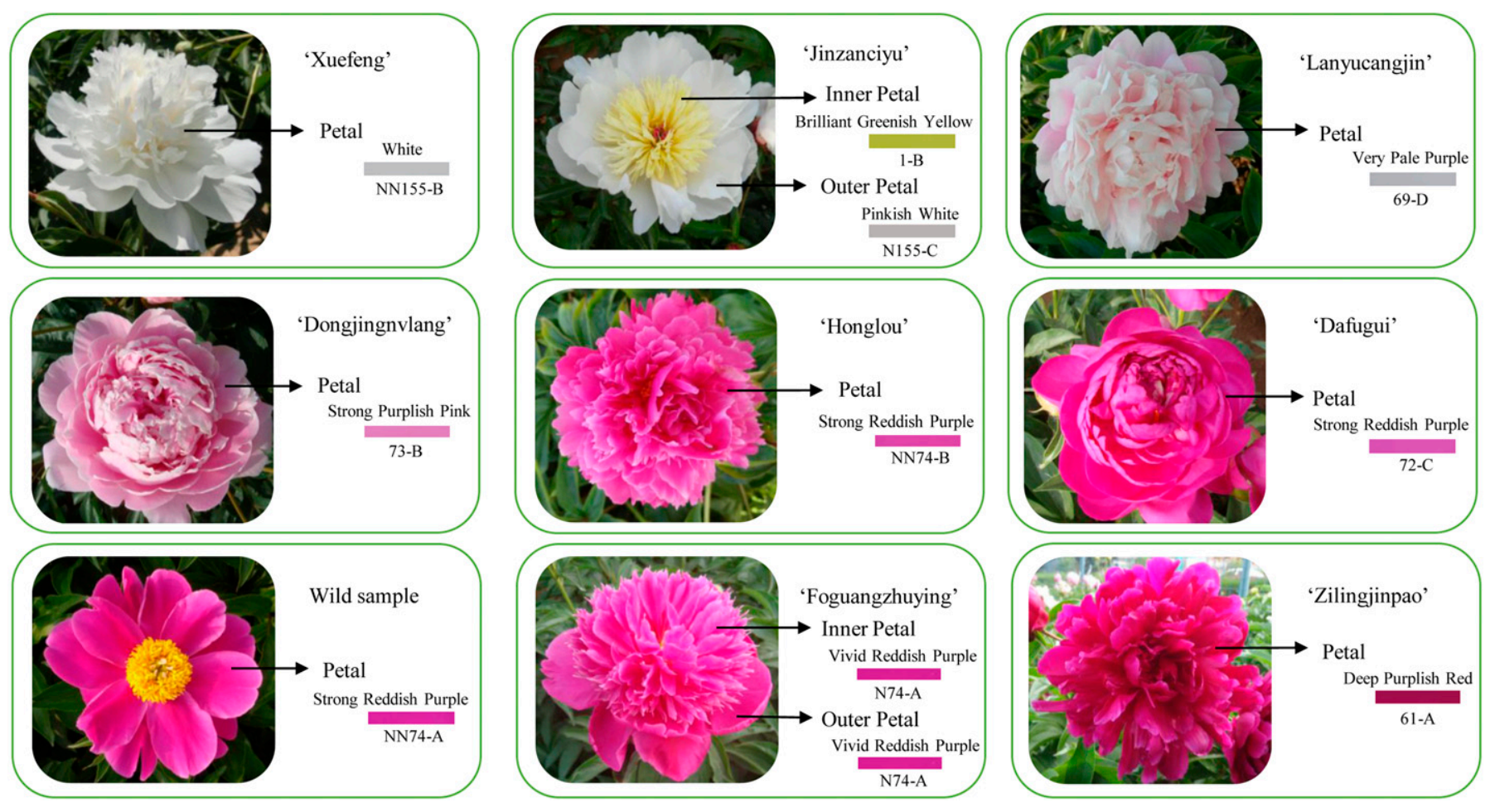

Fig. 1. Flower and Royal Horticultural Society Color Chart (Royal Horticultural Society, London, UK) value of herbaceous peony. 

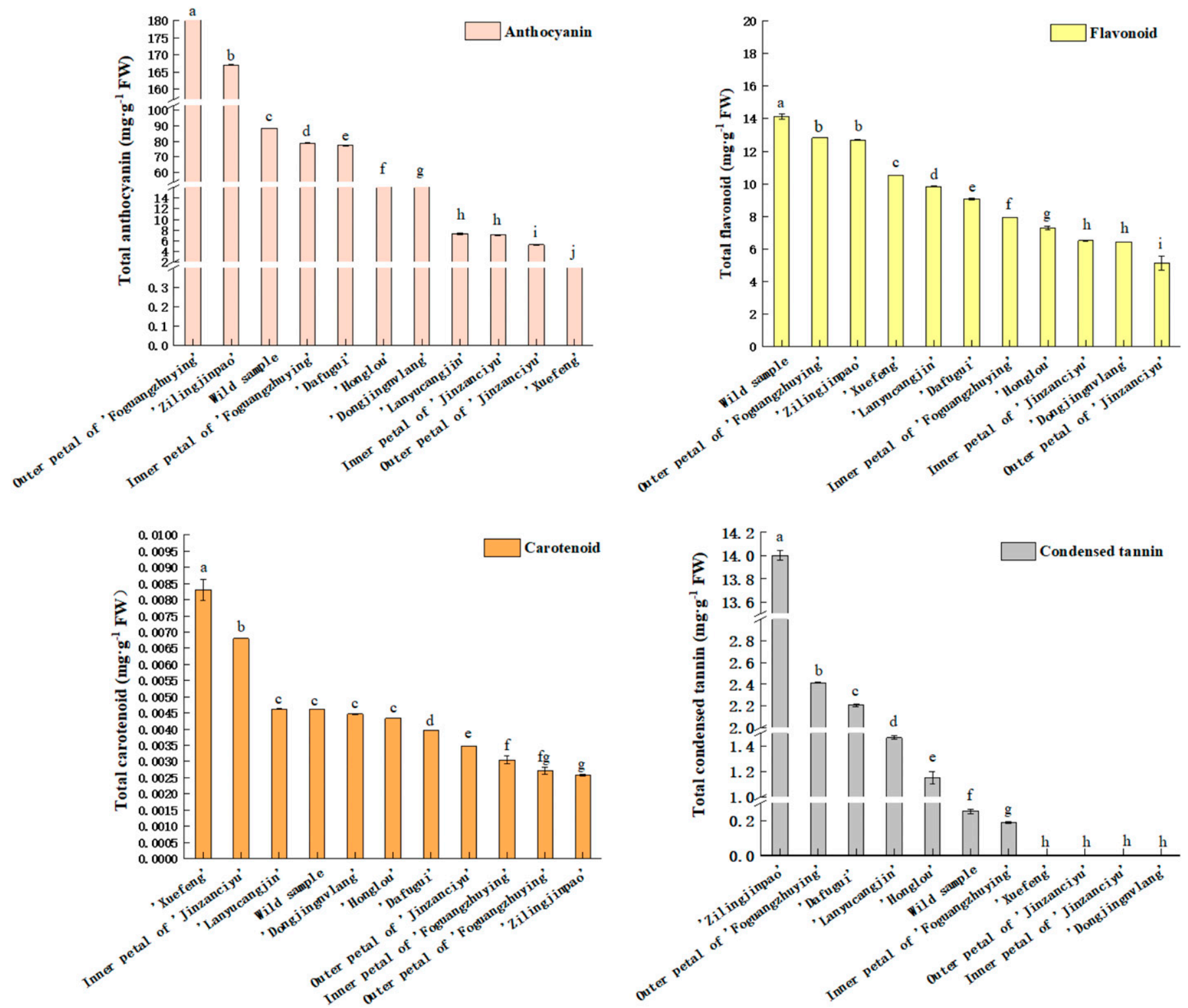

Fig. 2. Total amount of pigments in herbaceous peony petals. FW = fresh weight.

Table 1. Composition and content of anthocyanins in herbaceous peony petals.

\begin{tabular}{|c|c|c|c|c|c|c|c|c|c|}
\hline \multirow[b]{2}{*}{ Color group } & \multirow[b]{2}{*}{ Sample } & \multicolumn{8}{|c|}{ Content (mg/100 g FW) } \\
\hline & & Pn3G5G & Cy3G5G & Pg3G5G & Dp3G5G & Pn3G & Cy3G & $\mathrm{Pg} 3 \mathrm{G}$ & $\mathrm{Dp} 3 \mathrm{G}$ \\
\hline White & 'Xuefeng' & 0.155 & 0.000 & 0.179 & 0.000 & 0.000 & 0.000 & 0.000 & 0.000 \\
\hline Pinkish white & Outer petal of 'Jinzanciyu' & 0.196 & 0.033 & 0.052 & 0.000 & 0.000 & 0.000 & 0.000 & 0.000 \\
\hline Pale purple & 'Lanyucangjin' & 2.683 & 0.000 & 0.057 & 0.000 & 0.000 & 0.098 & 0.000 & 0.000 \\
\hline Purplish pink & 'Dongjingnvlang' & 11.715 & 2.378 & 2.556 & 0.000 & 0.000 & 0.000 & 0.124 & 0.000 \\
\hline Reddish purple & Wild sample & 61.824 & 3.861 & 4.165 & 0.000 & 0.326 & 0.000 & 0.394 & 0.000 \\
\hline Reddish purple & 'Dafugui' & 56.175 & 7.596 & 7.561 & 0.000 & 0.014 & 0.000 & 0.060 & 0.000 \\
\hline Reddish purple & Outer petal of 'Foguangzhuying' & 137.367 & 12.815 & 8.077 & 0.000 & 0.231 & 0.000 & 1.156 & 0.000 \\
\hline Reddish purple & Inner petal of 'Foguangzhuying' & 48.988 & 2.280 & 4.136 & 0.000 & 0.011 & 0.000 & 1.064 & 0.000 \\
\hline Purplish red & 'Zilingjinpao' & 4.801 & 0.151 & 1.039 & 0.000 & 0.000 & 0.000 & 0.000 & 0.057 \\
\hline
\end{tabular}

$\overline{\mathrm{FW}}=$ fresh weight; Pn3G5G = peonidin-3,5-di-O-glucoside; Cy3G5G = cyanidin-3,5-di-O-glucoside; Pg3G5G = pelargonidin-3,5-di-Oglucoside; Dp3G5G = delphinidin-3,5-di-O-glucoside; Pn3G = peonidin-3-O-glucoside; Cy3G = cyanidin-3-O-glucoside; Pg3G = pelargonidin3-O-glucoside; Dp3G = delphinidin-3-O-glucoside. 
main anthocyanins in pale-purple 'Lanyucangjin', and Pn3G5G and $\mathrm{Pg} 3 \mathrm{G} 5 \mathrm{G}$ were the main anthocyanins in purplish pink 'Dongjingnvlang'. Among the reddish purple samples, Pn3G5G and Pg3G5G were the main anthocyanins in the wild sample and the inner petals of 'Foguangzhuying', $\mathrm{Cy} 3 \mathrm{G}$ and Cy3G5G were the main anthocyanins in 'Honglou', and Pn3G5G and Cy3G5G were the main anthocyanins in 'Dafugui' and the outer petals of 'Foguangzhuying'. Pn3G5G and Pg3G5G were the main anthocyanins in purplish red 'Zilingjinpao'. Cy3G was only detected in pale-purple 'Lanyucangjin' and reddish purple 'Honglou', and Dp3G was only detected in purplish red 'Zilingjinpao'.

The TF was the greatest in the wild sample and the least in the pinkish white petals of 'Jinzanciyu' (Fig. 2). The components and contents of the flavonoids are shown in Table $2 . \mathrm{Km} 7 \mathrm{G}$ and Qu3G were the main flavonoids in white 'Xuefeng', and Is3G and $\mathrm{Km} 7 \mathrm{G}$ were the main flavonoids in pinkish white 'Jinzanciyu' (outer petals). The main flavonoids of the yellow inner petals of 'Jinzanciyu' were Qu3G and Is3G. Km7G and Qu3G were the main flavonoids in pale-purple 'Lanyucangjin' and purplish pink 'Dongjingnvlang'. Among the reddish purple samples, the main flavonoids in the wild sample and the outer petals of 'Foguangzhuying' were Qu3G and Is3G, Km7G and Qu3G in 'Honglou' and 'Dafugui', and Is3G and $\mathrm{Km} 7 \mathrm{G}$ in the inner petals of 'Foguangzhuying'. The main flavonoids in purplish red 'Zilingjinpao' were $\mathrm{Km} 7 \mathrm{G}$ and Qu3G. The contents of Qu7G and $\mathrm{Lu} 7 \mathrm{G}$ were the greatest in the reddish purple wild sample, and My3R was the greatest in 'Honglou'. Km3G and Is3Gal were not detected in any of the samples, and My3R was not detected in the reddish purple wild sample or purplish pink 'Dongjingnvlang'.

Trace amounts of carotenoids were detected in all samples (Fig. 2). The carotenoid content was the greatest in white 'Xuefeng', the second-greatest in yellow 'Jinzanciyu' (inner petals), and the least in purplish red 'Zilingjinpao'. As shown in Table 3, lutein was the main carotenoid component of all the cultivars. The contents of lutein and $\beta$-carotene were the greatest in reddish purple 'Honglou' and second-greatest in yellow 'Jinzanciyu' inner petals.

Petal microstructure. As shown in Fig. 3A, the petals were composed mainly of two layers of epidermal cells and parenchymal tissue. The upper and lower epidermal cells are similar in morphology and tightly arranged. The parenchymal cells are loosely arranged, and their intercellular spaces are visible. Petal thickness (PT) ranged from 0.11 to $0.44 \mathrm{~mm}$ (Table 4). The largest PT was observed in pale-purple 'Lanyucangjin', reddish purple 'Foguangzhuying' (outer petals), and purplish red 'Zilingjinpao'. The outer petals of 'Foguangzhuying' and 'Lanyucangjin' had thicker parenchymal tissues, and the outer petals of 'Foguangzhuying' and 'Zilingjinpao' had thicker cytoderms. The epidermal cells had four distinct shapes: flat, dome, elongated dome, and papillate. Two types of epidermal cells were observed in pale-purple 'Lanyucangjin', purplish pink 'Dongjingnvlang', and the reddish purple wild sample, but there was only one cell type in the other samples (Fig. 3B; Table 4). In 'Jinzanciyu', the shape and color of the inner and outer petals were different, and the shape of their epidermal cells also varied. The shape of the inner and outer petals was also different in 'Foguangzhuying', but the color of the petals and the shape of the epidermal cells were consistent. In 'Jinzanciyu', 'Lanyucangjin', the wild sample, 'Dafugui', and the inner petals of 'Foguangzhuying', white stripes were noted on the outer surface of the epidermal cell wall (Fig. 3C).
Moisture Content And PH. The MC of the tested samples varied (Fig. 4). The MC was the greatest in reddish purple 'Honglou' (83.04\%) and the least in reddish purple 'Foguangzhuying' inner petals $(70.25 \%)$. The MC of the white, pinkish white, pale purple, and purplish pink samples was greater than that of the yellow, purplish red, and most reddish purple samples (except 'Honglou').

The results in Fig. 4 show that the cell sap of the samples was slightly acidic, with a $\mathrm{pH}$ between 5.84 and 5.05. Yellow 'Jinzanciyu' (inner petals) had the highest $\mathrm{pH}$ (5.84), whereas reddish purple 'Honglou' had the lowest $\mathrm{pH}$ (5.05). The cell sap $\mathrm{pH}$ of the yellow, white, pinkish white, pale-purple, and purplish pink samples was higher than that of the purplish red and most reddish purple samples (except for the inner petals of 'Foguangzhuying').

SOluble SUGAR AND SOluble PROTEIN CONTENTS. The soluble sugar content of the reddish purple wild sample was the greatest $\left(6.96 \mathrm{mg} \cdot \mathrm{g}^{-1}\right)$, whereas that of the yellow 'Jinzanciyu' inner petals was the least $\left(3.78 \mathrm{mg} \cdot \mathrm{g}^{-1}\right.$; see Fig. 5). There was no difference in the soluble sugar content of pale purplish 'Lanyucangjin' and reddish purple 'Foguangzhuying' (outer petals), but there were significant differences between that of the other samples. The soluble protein content was the greatest in the reddish purple 'Foguangzhuying' inner petals (25.17 $\left.\mathrm{mg} \cdot \mathrm{g}^{-1}\right)$ and the least in the outer petals of 'Foguangzhuying' $\left(11.09 \mathrm{mg} \cdot \mathrm{g}^{-1}\right)$. The soluble sugar and soluble protein contents of the 'Foguangzhuying' inner petal were significantly greater than those of the outer petals, but the pattern was reversed between the petal types of 'Jinzanciyu'.

Condensed TANNIn CONTENT. There were significant differences in $\mathrm{Ct}$ (Fig. 2). The Ct in purplish red 'Zilingjinpao' was the greatest $\left(14.00 \mathrm{mg} \cdot \mathrm{g}^{-1}\right)$, whereas that in the reddish purple 'Foguangzhuying' inner petals was the least $\left(0.19 \mathrm{mg} \cdot \mathrm{g}^{-1}\right)$. In the other samples, the $\mathrm{Ct}$ was $\leq 2.41 \mathrm{mg} \cdot \mathrm{g}^{-1}$.

Correlation analysis. The results of the correlation analysis are shown in Table 5. The TA correlated positively with the TF, PT, and cytoderm thickness (CT), but correlated negatively with the TC. Moreover, TF correlated positively with PT. The Ct correlated negatively with the MC. There was a significant correlation between PT, parenchyma tissue thickness (PtT), and CT.

\section{Discussion}

EFFect of Pigments on Flower COLOR. The type and content of anthocyanin are critical factors influencing flower color. The flowers of blooming roses appear white when the anthocyanin content is low, but as the anthocyanin content increases, the flowers gradually turn pink and purple (Zhang et al., 2015b). In tree peony, flower color deepens as the TA increases, and the composition of anthocyanin also affects flower color; paeoniflorin makes the petals red and purple whereas cyanidin makes the petals peach (Liu et al., 2019; Wang and Yuan, 2015). The accumulation of delphinidin can significantly increase the reddish color of petals; a greater delphinidin content in daylily (Hemerocallis L.) petals results in a reddish brown appearance (Huang, 2013). In our study, deeper color in the white, pinkish white, pale-purple, purplish pink, and reddish purple samples was associated with a greater TA. The TA was the least in white 'Xuefeng' and the greatest in reddish purple 'Foguangzhuying' (outer petals). The diversity of anthocyanin components in white 'Xuefeng', pinkish white 'Jinzanciyu' (outer petals), and pale-purple 'Lanyucangjin' was 
Table 2. Composition and content of flavonoids in herbaceous peony petals.

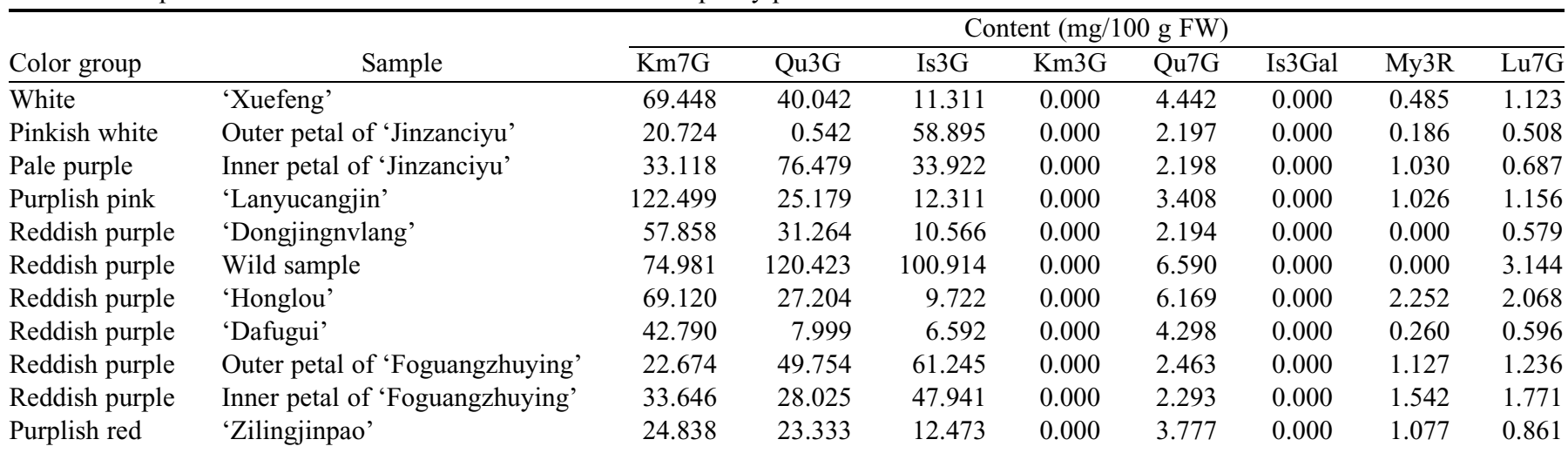

$\overline{\mathrm{FW}}$ = fresh weight; Km7G = kaempferol-7-O-glucoside; Qu3G = quercetin-3-O-glucoside; Is3G = isorhamnetin-3-O-glucoside; Km3G = kaempferol-3-O-glucoside; Qu7G = quercetin-7-O-glucoside; Is3Gal = isorhamnetin-3-O-galactoside; My3R = myricetin-3-O-rhamnoside; $\mathrm{Lu} 7 \mathrm{G}=$ luteolin-7-O-glucoside.

Table 3. Composition and content of carotenoids in herbaceous peony petals.

\begin{tabular}{llcc}
\hline & \multicolumn{1}{c}{ Sample } & \multicolumn{1}{c}{ Content (mg/100 g FW) } \\
\cline { 2 - 4 } Color group & \multicolumn{1}{c}{ Lutein } & 0.000400 \\
White & 'Xuefeng' & 0.000510 & 0.000200 \\
Pinkish white & Outer petal of 'Jinzanciyu' & 0.002014 & 0.000291 \\
Pale purple & Inner petal of 'Jinzanciyu' & 0.001061 & 0.000387 \\
Purplish pink & 'Lanyucangjin' & 0.000340 & 0.000214 \\
Reddish purple & 'Dongjingnvlang' & 0.000204 & 0.000240 \\
Reddish purple & Wild sample & 0.002420 & 0.000134 \\
Reddish purple & 'Honglou' & 0.000287 & 0.000823 \\
Reddish purple & 'Dafugui' & 0.000195 & 0.000186 \\
Reddish purple & Outer petal of 'Foguangzhuying' & 0.000627 & 0.000171 \\
Reddish purple & Inner petal of 'Foguangzhuying' & 0.000560 & 0.000102 \\
Purplish red & 'Zilingjinpao' &
\end{tabular}

$\overline{\mathrm{FW}}=$ fresh weight.

A

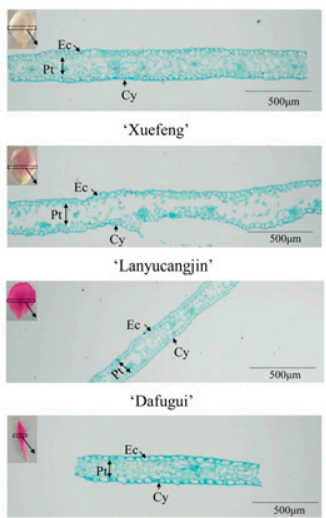

Inner petal of 'Foguangzhuying'

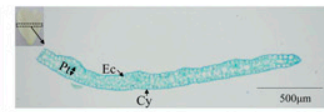
Outer petal of 'Jinzanciyu'

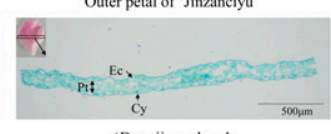
'Dongjingnvlang'

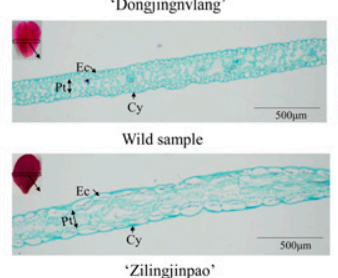

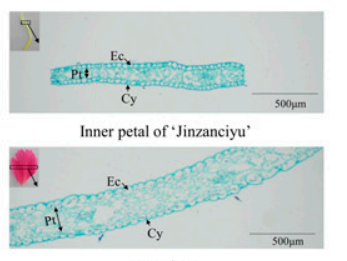

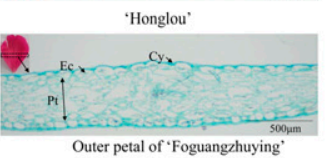

Outer petal of 'Foguangzhuying'

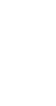

B
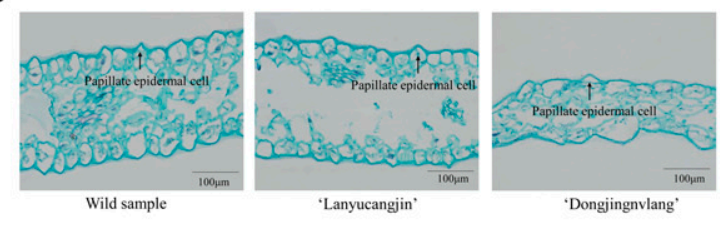

C
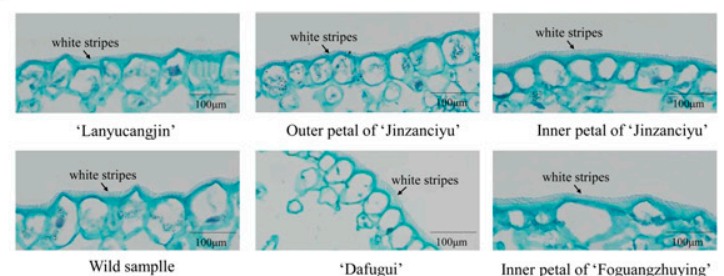

Inner petal of 'Foguangzhuying'

Fig. 3. Petal microstructure of herbaceous peony petals. (A) Petal cross-section at $\times 40$ magnification. (B) Papillate epidermal cell of the petals at $\times 200$ magnification. (C) White stripes on the outside of the petals at $\times 200$ magnification.

less than that in the other color samples. Reddish purple 'Honglou' had a greater Cy3G content than the other reddish purple samples; the color of 'Honglou' is redder than 'Dafugui', but lighter than the wild sample and 'Foguangzhuying'. A small amount of Dp3G was detected in purplish red 'Zilingjinpao', but not in the other cultivars.

Flavonoids and flavonols can make the tree peony appear white, pale yellow, or yellow. Kaempferol and luteolin may serve 


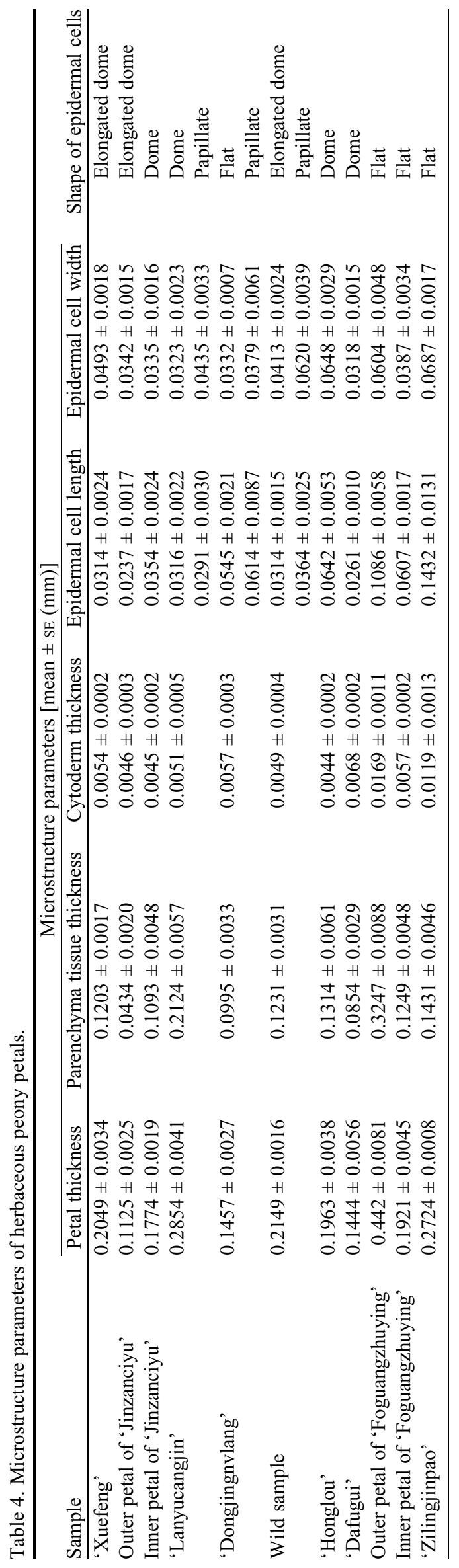




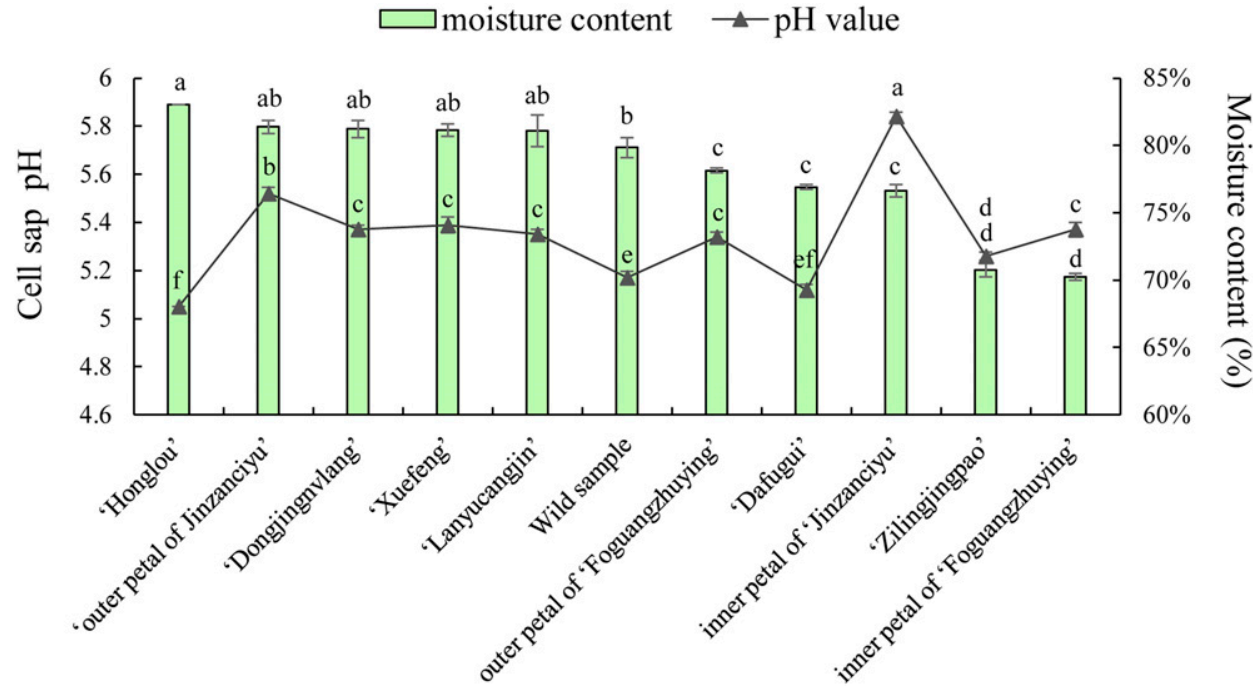

Fig. 4. Cell sap pH and water content of herbaceous peony petals.

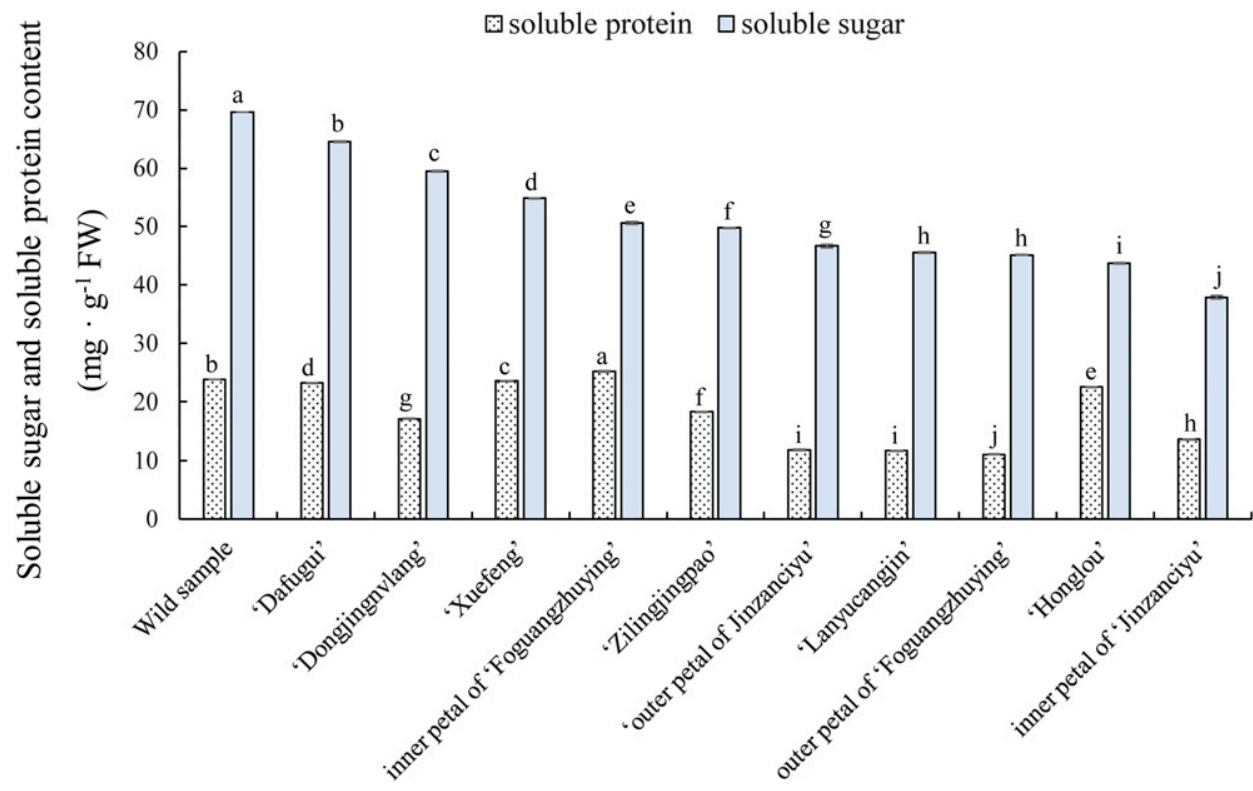

Fig. 5. Soluble sugar and soluble protein content of herbaceous peony petals. FW = fresh weight.

Carotenoids appear yellow or orange in plant petals. Studies of the stock plant and bud mutational branches of Osmanthus (Osmanthus fragrans Lour.) have shown that carotenoids are the key pigments of petal color change (Wang et al., 2017). However, changes in rose flower color were not the result of carotenoids (Zhang et al., 2015b). Carotenoids were detected in all samples tested in our study, and the proportion of lutein was relatively high in the yellow petals of 'Jinzanciyu'. We speculate that the accumulation of lutein was related to the formation of yellow petals in 'Jinzanciyu'.

EFFect of petal structure on FLOWER COLOR. The shape of plant epidermal cells affects the appearance of color. Mudalige et al. (2003) observed four types of epidermal cells in dendrobium (Dendrobium Sw.) petals: flat, dome, elongated dome, and papillate. When the epidermal cells of butterfly orchid (Phalaenopsis $\mathrm{Bl}$.) petals have a tapered structure, the ratio of incident light entering the cells increases, which aids the appearance of pigments within the cells (Xiao et al., 2017).

In our study, the pale-purple 'Lanyucangjin', purplish pink 'Dongjingnvlang', and reddish purple wild sample had papillate epidermal cells, and their colors were brighter. The epidermal cell morphology of the wild sample is different from the other reddish purple samples; this may be a characteristic of the wild species. The microstructure and flower color of the inner and outer petals of 'Jinzanciyu' and 'Foguangzhuying' showed that the epidermal cell shape might affect the

as accessory pigments to reduce the purity of red, changing the color to pink and/or purple (Wang and Yuan, 2015). Studies have shown that quercetin is the primary pigment component of the yellow petals of yellow camellia ( $\mathrm{Li}$ et al., 2019; Tanikawa et al., 2008). In our study, the main flavonoids were, for the most part, consistent. The Qu3G content in yellow 'Jinzanciyu' (inner petals) was greater than that in the other samples, suggesting that Qu3G plays an essential role in yellow-petal production. The contents of $\mathrm{Km} 7 \mathrm{G}$ and $\mathrm{My} 3 \mathrm{G}$ in pale-purple 'Lanyucangjin' was greater than those in purplish pink 'Dongjingnvlang', and the contents of Lu7G and My3G were relatively high in reddish purple 'Honglou', which is lighter than the other reddish purple samples. These results indicate that flavonoids (especially $\mathrm{Km} 7 \mathrm{G}$, Lu7G, and My3G) have a hypochromic effect on flower color in the herbaceous peony, making the flowers appear lighter in color. These results are consistent with those of Zhong et al. (2012). appearance of color, and PT correlated positively with TA and TF. Moreover, the PT and epidermal cell volume of purplish red 'Zilingjinpao' were greater than those in the other samples. This may affect the coloration of the petals. The white stripes on the outer surface of some tree peony petals may be attributed to a raised cuticle (Zhang et al., 1998), which could explain the variable texture of the petals.

EFfect of PETAL PH AND MC ON Flower COLOR. The cell sap $\mathrm{pH}$ of the petal plays an important role in the presence of anthocyanins in the plant organs (Zhuang et al., 2018). In yunnan camellia (Camellia reticulata Lindl.) petals, the $\mathrm{pH}$ of deep-red petals was less than that of pink petals (Xue et al., 2015); and in yellow camellia, when the cell sap pH approaches neutrality, the flowers turn yellow (Jiang et al., 2019). In our study, yellow 'Jinzanciyu' inner petals had the highest $\mathrm{pH}$, and the $\mathrm{pH}$ of pinkish white 'Jinzanciyu' (outer petals), white 'Xuefeng', purplish pink 'Dongjingnvlang', and pale-purple 
Table 5. Correlation analysis of physiological indexes of herbaceous peony petals.

\begin{tabular}{|c|c|c|c|c|c|c|c|c|c|c|c|}
\hline \multirow[b]{2}{*}{ Index } & \multicolumn{11}{|c|}{ Correlation coefficient } \\
\hline & TA & $\mathrm{TF}$ & $\mathrm{TC}$ & $\mathrm{Ct}$ & $\mathrm{MC}$ & $\mathrm{pH}$ & SS & SP & PT & PtT & $\mathrm{CT}$ \\
\hline TA & 1 & & & & & & & & & & \\
\hline $\mathrm{TF}$ & $0.656^{*}$ & 1 & & & & & & & & & \\
\hline $\mathrm{TC}$ & $-0.679 *$ & -0.141 & 1 & & & & & & & & \\
\hline $\mathrm{Ct}$ & 0.515 & 0.361 & -0.433 & 1 & & & & & & & \\
\hline $\mathrm{MC}$ & -0.499 & -0.224 & 0.412 & $-0.661^{*}$ & 1 & & & & & & \\
\hline $\mathrm{pH}$ & -0.395 & -0.419 & 0.382 & -0.226 & -0.107 & 1 & & & & & \\
\hline SS & 0.108 & 0.383 & -0.014 & -0.067 & 0.045 & -0.533 & 1 & & & & \\
\hline SP & -0.002 & 0.171 & 0.163 & 0.095 & -0.214 & -0.538 & 0.584 & 1 & & & \\
\hline PT & $0.686^{*}$ & $0.680^{*}$ & -0.285 & 0.181 & -0.144 & -0.121 & -0.263 & -0.363 & 1 & & \\
\hline $\mathrm{PtT}$ & 0.591 & 0.566 & -0.251 & 0.019 & -0.045 & -0.11 & -0.287 & -0.389 & $0.974 * *$ & 1 & \\
\hline $\mathrm{CT}$ & $0.885 * *$ & 0.565 & -0.508 & -0.017 & -0.356 & -0.131 & -0.131 & -0.328 & $0.823 * *$ & $0.749 * *$ & 1 \\
\hline
\end{tabular}

*,**Significant at $P \leq 0.05$ or 0.01 , respectively.

$\mathrm{TA}=$ total amount of anthocyanins; $\mathrm{TF}=$ total amount of flavonoids; $\mathrm{TC}=$ total amount of carotenoids; $\mathrm{Ct}=$ condensed tannin content; $\mathrm{MC}=$ moisture content; $\mathrm{SS}=$ soluble sugar; $\mathrm{SP}=$ soluble protein $; \mathrm{PT}=$ petal thickness; $\mathrm{PtT}=$ parenchymal tissue thickness $; \mathrm{CT}=$ cytoderm thickness .

'Lanyucangjin' were all higher than that of purplish red 'Zilingjinpao' and most reddish purple samples (except 'Foguangzhuying' inner petals).

The MC of the petals also affects flower color. In golden camellia, the water content of the petals had a slight negative correlation with flower color, indicating that high moisture in the petals interferes with flower color formation (Jiang et al., 2019). In our study, the MC of the white, pinkish white, palepurple, and purplish pink samples was greater than that of the yellow, purplish red, and most reddish purple samples (except 'Honglou'). This observation is consistent with the results from golden camellia plants (Jiang et al., 2019) and may be related to the dilution of biochemical substances in the cell sap.

EFFECTS OF SOLUBLE SUGAR AND SOLUBLE PROTEIN ON FLOWER COLOR. The contents of soluble sugar and soluble protein in cells affects flower color. Currently, the relationships between soluble sugar, soluble protein, and flower color are inconsistent. A study on Magnolia wufengensis L.Y. Ma et L.R. Wang showed that an increase in the contents of anthocyanin and soluble sugar, and a decrease in the content of soluble protein were associated with deepened color (He et al., 2010). In medicinal chrysanthemum, an increase in the soluble sugar content was associated with a decrease in the anthocyanin content during flower development (Ma et al., 2016).

The correlation analysis used in our study showed there were no significant correlations between the contents of soluble sugar and soluble protein, and the other physiological indices.

EFFECT OF CONDENSED TANNIN ON FLOWER COLOR. Condensed tannins are derivatives of flavanols (Rasmussen et al., 2005) and are often used as complementary substances to change the color of wine. In the purple sweetpotato [Ipomoea batatas (L.) Lam.], tannins improve the stability of anthocyanin and make its anthocyanin solution darker (Zhu et al., 2006).

The results from our study showed that the $\mathrm{Ct}$ in the purplish red sample was much greater than in the other samples. This suggests that the accumulation of condensed tannins is beneficial to the formation of purplish red color in herbaceous peony.

\section{Conclusions}

Taken together, our results demonstrate that the flower color of herbaceous peony is influenced by numerous factors, and that the content and composition of the pigments are the most important. The TA of the white and pinkish white cultivars was the lowest. In the pale-purple, purplish pink, and reddish purple cultivars, deeper color was associated with a greater TA. The Pg3G5G content was the greatest in white 'Xuefeng', the Cy3G content was the greatest in reddish purple 'Honglou', and the Pn3G5G content was the greatest in the other tested samples. The composition of flavonoids was consistent across samples; quercetin, isorhamnetin, and kaempferol were the main components. $\mathrm{Km} 7 \mathrm{G}$, My3R, and Lu7G may show hypochromic effects in herbaceous peony flower color formation. All the samples contained few carotenoids, and the lutein content was greater than that of $\beta$-carotene. The content of Qu3G and lutein in yellow 'Jinzanciyu' (inner petals) was relatively high, so we speculate that the accumulation of Qu3G and lutein is essential to the appearance of yellow flower color

Other physiological indicators, such as the tissue structure and intracellular environment of the petals, affect the content, concentration, and stability of the pigments, all of which influence the flower color of herbaceous peony. The TA and TF of the cultivars correlated positively with PT, and the samples with papillate epidermal cells in the petals had a brighter color. A greater MC was associated with lighter coloration. The samples with lower cell sap $\mathrm{pH}$ or greater Ct's often showed darker colors, which may be a result of greater anthocyanin stability in the petals.

We analyzed comprehensively the color formation mechanisms of herbaceous peony petals for the contents and composition of the pigments, petal tissue structure, intracellular environment, and biochemical substances. The results presented here add to our limited knowledge of flower color formation; but, because only a limited number of samples were tested, future studies require the inclusion of more plant types. The key genes of the anthocyanin metabolism pathway should be studied to provide physiological and molecular references for herbaceous peony color breeding.

\section{Literature Cited}

Cang, J. and H.J. Zhao. 2013. Determination of soluble sugar by anthranone colorimetry, p. 85-158. In: J. Cang (ed.). Experimental course of plant physiology. Higher Education Press, Beijing, China.

Cheng, M.L. 2008. Flower bud differentiation process and effects of exogenous GA3 on the flower bud development of introduced Paeonia lactiflora. MS thesis, Hunan Agricultural University, Hunan, China.

He, Y.Q., L.Y. Ma, and Z.Y. Sang. 2010. Preliminary study on formation of flower color in Magnolia wufengensis. Acta Botanica Boreali Occidentalia Sinica 30:2252-2257.

Huang, X.L. 2013. Research of flower color and petal flavonoids of Hemerocallis. MS thesis, Hebei Agriculture University, Hebei, China.

Jia, N., Q.Y. Shu, L.S. Wang, H. Du, Y.J. Xu, and Z.A. Liu. 2008. Analysis of petal anthocyanins to investigate coloration mechanism in herbaceous peony cultivars. Scientia Hort. 117:167-173. 
Jiang, L.N., J.Y. Li, R. Tong, L.B. He, L. Zhang, Z.H. Li, and X.N. Huang. 2019. Relationship between flower color and important cellular environment elemental factors in yellow Camellia. Guihaia 39:1609-1612.

Lapidot, T., S. Harel, B. Akiri, R. Granit, and J. Kanner. 1999. pHDependent forms of red wine anthocyanins as antioxidants. J. Agr. Food Chem. 47:67-70.

Li, H.S., Q. Sun, and S.J. Zhao. 2000. Determination of chlorophyll content, p. 134-138. In: H.S. Li and Q. Sun (eds.). The experiment principle and technique on plant physiology and biochemistry. Higher Education Press, Beijing, China.

Li, Q., J. Xu, C. Gao, J. Lu, G. Du, and X. Sun. 2018. The taxonomic key of 63 herbaceous peony cultivars. Chinese Agr. Sci. Bull. 34:51-59.

Li, X.L., J.T. Wang, Z.Y. Sun, J. Wang, H.F. Yin, Z.Q. Fan, J.Y. Li, C.J. Jiang, and X.N. Huang. 2019. Flavonoid components and their relationship with flower colors in five species of Camellia section Chrysantha. Chinese J. Ecol. 38:961-966.

Liu, L., D.Q. Zhao, and J. Tao. 2019. Research progress on influential factors and regulation of tree peony flower color formation. Plant Physiol. J. 55:925-931.

Ma, C.H., J. Chu, S.X. Zhou, L.C. Fei, Y. Qi, and Q. Xiao. 2016. Effects of enhanced UV-B radiation on the nutritional and active ingredient contents during the floral development of medicinal chrysanthemum. J. Photochem. Photobiol. B 158:228-234.

Mudalige, R.G., A.R. Kuehnel, and T.D. Amore. 2003. Pigment distribution and epidermal cell shape in Dendrobium species and hybrids. HortScience 38:573-577.

Rasmussen, S.E., H. Frederiksen, K.S. Krogholm, and L. Poulsen. 2005. Dietary proanthocyanidins: Occurrence, dietary intake, bioavailability, and protection against cardiovascular disease. Mol. Nutr. Food Res. 49:159-174.

Royal Horticultural Society. 2015. Royal Horticultural Society Color Chart. 6th ed. Royal Horticultural Society, London, UK.

Tanikawa, N., T. Kashiwabara, A. Hokura, T. Abe, M. Shibata, and M. Nakayama. 2008. A peculiar yellow flower coloration of camellia using aluminum-flavonoid interaction. J. Jpn. Soc. Hort. Sci. 77:402-407.

Wang, X.Q. 2015. Phenolic metabolism of red-fleshed apples and its response to stress. PhD diss., Northwest A\&F University, Yangling, China. Wang, Y.G., Y.B. Luo, C. Zhang, J.X. Fu, S.Q. Hu, and H.B. Zhao. 2017. Flower color and pigment composition in the petals of bud mutation and its stock plant of Osmanthus fragrans 'Jingui'. Acta Horticulturae Sinica 44:528-536.

Wang, L.Y. and T. Yuan. 2015. Anthocyanin of peony, p. 197-209. In: L.Y. Wang (ed.). Map of Chinese peony species (continued). China Forestry Press, Beijing, China.

Xiao, W.F., Z. Li, H.M. Chen, and D.B. Lv. 2017. Comparing the petal microstructure of different color Phalaenopsis. Chinese Agr. Sci. Bull. 33:104-111.

Xue, Y.L., Q.S. Zhao, Y. Huang, Z. Liu, L.Q. Wu, C.F. Xi, J.B. Li, and J.Y. Li. 2015. Research on relationship between floral colors and intracellular environment of Camellia reticulata Lindl. J. Yunnan Agr. Univ. 30:455-463.

Yang, N., K.G. Zhao, X. Li, R. Zhao, M.Z. Aslam, L. Yu, and L.Q. Chen. 2018. Comprehensive analysis of wintersweet flower reveals key structural genes involved in flavonoid biosynthetic pathway. Gene 676:279-289.

Yao, S.P. and X.N. Ti. 2010. Optimization of assaying conditions about condensed tannin in cotton. J. Xijiang Agr. Univ. 33:339342.

Yoshida, K., N. Miki, K. Momonoi, M. Kawachi, K. Katou, Y. Okazaki, N. Uozumi, M. Maeshima, and T. Kondo. 2009. Synchrony between flower opening and petal-color change from red to blue in morning glory, Ipomoea tricolor cv. Heavenly Blue. P. Jpn. Acad. B Phys. 85:87-97.

Yu, Q.Y. 2014. Experiment for determination of soluble protein in plant tissues, p. 17-19. In: Q.Y. Yu (ed.). Experimental course of plant physiology. Beijing Institute of Technology Press, Beijing, China.

Zhang, C., J.X. Fu, Y.J. Wang, S.L. Gao, D.N. Du, F. Wu, J. Guo, and L. Dong. 2015a. Glucose supply improves petal coloration and anthocyanin biosynthesis in Paeonia suffruticosa 'Luoyang Hong' cut flowers. Postharvest Biol. Technol. 101:73-81.

Zhang, L.X., Z.P. Shi, D.H. Liu, and X.Y. Zhou. 1998. A study on the dissection structure of the petal of Jasminum sambac. J. Hunan Agr. Univ. 5:33-37.

Zhang, L., Z.D. Xu, T.F. Tang, H. Zhang, and L.Y. Zhao. 2015 b. Analysis of anthocyanins related compounds and their biosynthesis pathways in Rosa rugosa ' $\mathrm{Zi}$ zhi' at blooming stages. Scientia Agricultura Sinica 48:2600-2611.

Zhang, X.P., M.Y. Zhao, J. Guo, L.Y. Zhao, and Z.D. Xu. 2018. Anatomical and biochemical analyses reveal the mechanism of double-color formation in Paeonia suffruticosa 'Shima Nishiki'. 3 Biotech. 420:3-9.

Zhao, C.L., W.M. Guo, and J.Y. Chen. 2005. Formation and regulation of flower color in higher plants. Chinese Bull. Bot. 22:70-81.

Zhao, D.Q., M.R. Wei, D. Liu, and J. Tao. 2016. Anatomical and biochemical analysis reveal the role of anthocyanins in flower coloration of herbaceous peony. Plant Physiol. Biochem. 102:97106.

Zhong, P.X., L.S. Wang, S.S. Li, Y.J. Xu, and M.L. Zhu. 2012. The changes of floral color and pigments composition during the flowering period in Paeonia lactiflora Pallas. Acta Horticulturae Sinica 39:2271-2282.

Zhu, H.M., Y.B. Han, Z.X. Gu, and G.J. Fan. 2006. Studies on the copigmentation effect of tannin on purple sweet potato anthocyanins. J. Nanjing Agr. Univ. 29:98-102.

Zhuang, W.B., T.Y. Liu, X.C. Shu, S.C. Qu, H.H. Zhai, T. Wang, F.J. Zhang, and Z. Wang. 2018. The molecular regulation mechanism of anthocyanin biosynthesis and coloration in plants. Plant Physiol. J. 54:1630-1644. 